\title{
Advanced Management Accounting Problems
}


Also by Kenneth P. Gee

Management Planning and Control in Inflation

Management Control and Information

(with R. Beresford Dew) 


\title{
ADVANCED MANAGEMENT ACCOUNTING PROBLEMS
}

\author{
Kenneth P. Gee \\ Professor of Accountancy \\ Department of Business and Administration \\ University of Salford
}

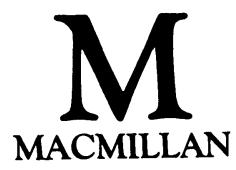


(C) Kenneth P. Gee 1986

All rights reserved. No reproduction, copy or transmission of this publication may be made without written permission.

No paragraph of this publication may be reproduced, copied or transmitted save with written permission or in accordance with the provisions of the Copyright Act 1956 (as amended).

Any person who does any unauthorised act in relation to this publication may be liable to criminal prosecution and civil claims for damages.

First published 1986

Published by

MACMILLAN EDUCATION LTD

Houndmills, Basingstoke, Hampshire RG21 2XS

and London

Companies and representatives

throughout the world

British Library Cataloguing in Publication Data Gee, Kenneth P.

Advanced management accounting problems.

1. Managerial accounting-Problems, exercises, etc.

I. Title 658.1' '511'076 HF5661

ISBN 978-0-333-36270-9

ISBN 978-1-349-18147-6 (eBook)

DOI 10.1007/978-1-349-18147-6 


\section{Contents}

Introduction

xiii

PART I: FULLY-WORKED PROBLEMS AND THEIR ANALYSIS

Standard Costing and Matrix Algebra

Primary Reference: Franks and Manes (1967)

1.1 Radium Dyestuffs Ltd

1.2 Analysis

Introduction

Computation of price, quantity and mixed variances

Computation of mix and yield variances

2 Stochastic Process Costing

Primary Reference: Corcoran and Leininger (1973)

2.1 Ottoline Electronics

2.2 Analysis

Development of a stochastic matrix

The fundamental matrix

Steady-state in-process inventories

Expected outputs of good and defective production

Expected variable cost per shift

19

Expected variable cost per assembly 
Standard deviations of good and defective output levels

Economics of test simplification

Economics of the 'zero defects' approach

3 Credit Management and Markov Chains:

Partial Balance Aging Method

Primary Reference: Corcoran (1978)

3.1 Stryford Ltd

3.2 Analysis 28

Development of a stochastic matrix $\quad 28$

Combining matrices by exponential weighting $\quad 32$

Credit Management and Markov Chains:

Modified Total Balance Aging Method

Primary References: Cyert, Davidson and

Thompson (1962); van Keulen, Spronk and

Corcoran (1981)

4.1 Michelsky Ltd

4.2 Analysis

Modified total balance aging 37

Expected value of receipts 39

Standard deviation of bad debts 41

Present value of receipts $\quad 42$

Steady-state investment in debtors $\quad 42$

Linear Programming and Decisions on Internal v. External Purchases of Services

Primary Reference: Baker and Taylor (1979)

5.1 Knockshinnock Mines Ltd

5.2 Analysis 47

Offer to supply electricity 47

Offer to supply electricity and water $\quad 50$

6 Linear Programming, Opportunity Losses and ex post Budgeting

Primary Reference: Demski (1967)

6.1 Araque Perfumes Ltd

6.2 Analysis

Introduction 
Traditional variance analysis $\quad 56$

Ex post variance analysis $\quad 58$

Intra-period relationships $\quad 61$

Shortcomings of the ex post approach $\quad 66$

\section{A Input-Output Analysis and Linear}

Programming

Primary Reference: Feltham (1970)

7A.1 Taumor Industries

7A.2 Analysis $\quad 72$

Computation of variable costs $\quad 72$

Solution by linear programming $\quad 76$

71 Input-Output Analysis and Linear

Programming with Purchasable Intermediate

Products and Joint Final Products

Primary Reference: Feltham (1970)

7B.1 Salmedge Products

7B.2 Analysis

Formulation and solution by linear programming

Use of Information Theory to Isolate

Substantial Variances

Primary Reference: Lev (1969)

8.1 Heversham Horticulture Ltd

8.2 Analysis

Fundamentals of information theory $\quad 87$

From probabilities to proportions $\quad 89$

Geographical variation in a product's sales $\quad 91$

Variation of sales by product for a given area $\quad 92$

Univariate variances 93

Breakdown to individual areas and products $\quad 94$

9 The Single-period Cost Variance Investigation Decision

Primary References: Capettini and Collins (1978);

Dyckman (1969)

9.1 Alston Glassworks

9.2 Analysis 
Establishment of terminology $\quad 99$

Break-even probabilities $\quad 100$

Revision of prior probabilities $\quad 101$

The quadratic equation approach $\quad 104$

Expected cost for a decision rule $\quad 107$

10 The Multi-period Cost Variance Investigation Decision

Primary Reference: Dittman and Prakash (1978)

10.1 Fitzroy Paper Products

10.2 Analysis

Introduction

A controlled Markov process

Steady-state probabilities

Determining long-term average cost per period

Costs with extremal policies and with perfect information

Solving the Fitzroy problem

Approximation to optimality of a fixed decision rule

11 Stochastic Cost-Volume-Profit Analysis and Decision Theory

Primary Reference: Jarrett (1973)

11.1 William Lehman Timber Ltd

11.2 Analysis

Elimination of the DD plant option

125

Posterior analysis

126

Preposterior analysis

Stochastic Cost-Volume-Profit Analysis:

Satisficing with Short Product Lives

Primary Reference: Ismail and Louderback (1979)

12.1 Knowsley Medical Products

12.2 Analysis

Introduction

Maximisation of expected profit

Analysis of financial risk

Maximising the probability of satisfactory profit

Fixed cost changes and satisficing decisions 
13 Stochastic Cost-Volume-Profit Analysis:

Choice Among Combinations of Products

Primary Reference: Dickinson (1974)

13.1 Barrow Gurney Orchards Ltd 145

13.2 Analysis 147

Choice of a strategy 147

Confidence limits for the break-even probability

$14 \quad \begin{aligned} & \text { Short-term Investment of Cash Balances } \\ & \text { Primary References: Mao and Sarndal (1978); }\end{aligned}$

Punter (1982)

14.1 Alvor Developments

14.2 Analysis

Introduction

Simplifying from the probability tree

Expected returns for alternative maturities

Dynamic programming

15 Payments Netting in Multinational Cash

Management

Primary Reference: Shapiro (1978)

15.1 Lintock Corporation

15.2 Analysis

Introduction

Payments netting

Mathematical programming and the Lintock problem

Primary References: Harvey (1976); McIntyre (1977)

16.1 Holt Electronics PLC

16.2 Analysis

Computing the break-even level with a single production line

Computing the break-even level with multiple production lines 
Forecasting output over the first year $\quad 184$

Forecasting output over subsequent years $\quad 185$

Sensitivity analysis on output forecasts $\quad 186$

Steady-state conditions $\quad 187$

17 Joint Product Decisions 190

Primary Reference: Amey (1984)

17.1 Cydilla Separators Ltd 190

17.2 Analysis 193

Specification of demand functions 193

Outline of the problem 193

Complementary slackness conditions $\quad 198$

Marginal conditions in the optimal solution $\quad 200$

\section{PART II: PROBLEMS FOR SELF-STUDY}

1 Arconate Ltd 205

2 Kleeford Distilled Compounds 208

3 Langdale Ltd 211

4 Firenza Associates 213

5 Remosense PLC 216

6 Shalmirane Ltd 218

7A Kerruish Tracers 222

7B Raistrick Ltd 226

8 Department of Transportation Analytical Offices 229

9 Star Chemical Company 231

10 Mansfield Pressings 234

11 Bulk Powder Producers Ltd 236

12 Bridgegate Foods 238

13 Galpen Cleansing Products 241

14 Maselia Ltd 243

15 Thornend Communication Systems PLC 247 
16 Claygill Holdings 249

17 Kwisant Oils 252

PART III: ANALYSIS OF PROBLEMS FOR SELF-STUDY

1 Arconate Ltd 257

2 Kleeford Distilled Compounds 262

3 Langdale Ltd 266

4 Firenza Associates 270

5 Remosense PLC 275

6 Shalmirane Ltd 278

7A Kerruish Tracers 283

7B Raistrick Ltd 288

8 Department of Transportation Analytical Offices 293

9 Star Chemical Company 296

10 Mansfield Pressings 301

11 Bulk Powder Producers Ltd 303

12 Bridgegate Foods 306

13 Galpen Cleansing Products 310

14 Maselia Ltd 314

15 Thornend Communication Systems PLC 322

16 Claygill Holdings 326

17 Kwisant Oils 333

Appendices

1 Checklist of Topics and Related Problems 339

2 Detailed References by Topic 346

3 Guides to Further Study 352

4 Suppliers of Software Packages 354 


\section{Introduction}

It is a fair generalisation to say that scholars in the field of management accounting may broadly be divided into two groups. These groups may be distinguished from each other by their implicit response to this question: from which disciplines should the study of management accounting draw most heavily? To this question, one group would reply 'psychology, sociology and general systems theory' while the other group would say 'statistics, operational research and microeconomics'. This book is firmly in the latter tradition; it could hardly be otherwise, since the former tradition is much more concerned with the description of contexts than it is with the analysis of problems. It would be foolish for either group of scholars to disparage the other - their roles are complementary. However, in recent years rather more of the academic work in management accounting has conformed to the positive, behavioural mould than has conformed to the normative, quantitative mould. This book represents a small movement in the direction of redressing this balance.

In making this movement, the book endeavours to fill what is currently a fairly substantial gap in the literature available to students and teachers of management accounting at second and third year undergraduate level. Once the first year background material in statistics and quantitative methods has been assimilated, it is a logical progression to apply this material to acceptably realistic management accounting problems. It is helpful if these problems are such as to provide practice in the use of the microcomputer, while at the same time they must illustrate the employment of techniques advanced in the research literature. 
The desirability of a significant computing content implies that the problems should not be so small as to give inadequate 'hands-on' practice, while the need to illustrate selected aspects of the research literature implies a requirement for close crossreferencing. Matters are further complicated by the fact that teachers differ in their identification of the most crucial papers within the literature, so that an approach placing restrictions upon the order in which topics can be dealt with may compel excessive attention to be paid to topics which are not conceived as being of central importance.

All of the issues mentioned above, but especially the last one, give rise to a need for something other than a conventional textbook to underpin the teaching of second and third year management accounting. A textbook which is to be used from 'cover to cover' in this area has to be very lengthy (and thus expensive) to cater exhaustively for the divergent emphases present in teaching. Moreover, a general purpose textbook cannot devote sufficient space to the development of realistically sized problems without compromising the interests of teachers who prefer to work through an approach which is not problem based, or whose students do not have access to the computing facilities required to handle substantial problems.

The gap in the literature faced by teachers who employ a quantitative, computational approach to the study of advanced management accounting is that there is no readily available set of problems which can be used in a flexible way to identify and illuminate those research studies having relatively immediate implications for the improvement of practice. This set of problems is intended to fill this gap. In doing so, it may also provide insights which help students (and managers) to visualise the associations between real world phenomena in management accounting and that part of the literature which addresses these phenomena sufficiently directly to enable problems to be written. Indeed, the author's aspirations extend a little further than the simple recognition by readers of a correspondence between their interests and the content of the problems presented here. It is hoped that the techniques used to solve the problems may in some cases be transferable, with adaptation, to ongoing industrial situations. The discipline imposed by the requirement that the institutional details of each problem must be spelled out is quite a stringent one; many 
ideas within the literature, such as those of agency theory, have had to be omitted from this book simply because no plausible mechanism could be found whereby managers could have in their possession the necessary information to enable analysis using these ideas to take place. Those problems which could be clothed with institutional detail must by definition be at least partially realistic the reader may judge whether the obtrusion of unrealistic, simplifying assumptions from that detail is such as to render a particular technique inapplicable to the everyday experience of industry and commerce.

The analysis of each of the problems here constitutes a selfcontained guide to the contents of the paper or papers which make up the Primary Reference(s) to that problem. Put in another way, the problems have been tailor-made to fit the Primary Reference(s), and to bring out all of their central features. There is thus no need, when using this book, to refer to any other exposition of the material than that in the papers with which it deals. It is, however, necessary to have access to some of the usual computer software for operational research and statistics. In dealing with specific problems, computations are required involving operations on matrices, linear programming and the solution of moderately sized systems of simultaneous equations. The author's computational experience has been confined to work on the Commodore PET and DEC Rainbow 100 microcomputers, thus restricting the guidance that may be offered on software. However, taking the DEC machine as approximating the 'state of the art', the following packages have been found to perform satisfactorily in dealing with the problems associated with the topics enumerated below:

Software package

OPTIMIZER (runs with MBASIC compiler on $\mathrm{CP} / \mathrm{M}$; requires $64 \mathrm{~K}$ of memory)

MINITAB (runs on CP/M $80 / 86$ with $64 \mathrm{~K}$ of memory)

\section{Application}

Deals with linear programming problems, can thus carry out some of the computations required by Topics 5, 6, 7A, 7B, 15.

Performs operations on matrices and can thus carry out some of the computations required by Topics 1 , 2, 3, 4, 7A, 7B 
TK!SOLVER 86 (runs on $\mathrm{CP} / \mathrm{M}$ with $128 \mathrm{~K}$ of memory)
Also a valuable general purpose
statistical package

Solves systems of simultaneous equations, and can thus carry out some of the computations required by Topic 17

Also useful in performing iterative calculations for Topic 16, and arithmetic for Topic 8

Turning from technical to personal matters, I am delighted to record my gratitude to Mrs Jean Waring, who typed the manuscript of this book in its many drafts with unfailing patience and efficiency. The finished book I dedicate to my wife, Hilary, without whose constant encouragement and support it could never have been written.

Kenneth P. Gee 